\title{
Maatschappelijk initiatief voor nieuwe scholen
}

\section{Over een verruiming van het richtingbegrip}

\author{
Hansko Broeksteeg
}

\begin{abstract}
Nederland kent een duaal onderwijsstelsel, een stelsel dat naast het openbaar, door de overheid geïnitieerd onderwijs ook bijzonder, door particulieren geïnitieerd onderwijs kent. Het duale onderwijsstelsel stamt uit 1848. ${ }^{1}$ In 1917 werd vervolgens de gelijkbekostiging grondwettelijk gegarandeerd: het bijzonder onderwijs wordt op gelijke voet bekostigd als het openbaar onderwijs. Dit jaar vieren wij dus het eeuwfeest daarvan. De gelijkbekostiging heeft bewerkstelligd dat grote groepen van de Nederlandse bevolking zelf onderwijs konden (laten) verzorgen en daarmee konden emanciperen. Daarmee kon de vrijheid van onderwijs ook praktische toepassing krijgen. Het grondrecht laat, althans in theorie, veel ruimte voor ouders en maatschappelijke organisaties om scholen te stichten, daaraan een richting te geven en deze in te richten.
\end{abstract}

Deze bijdrage onderzoekt eerst welke regels de overheid stelt aan de oprichting en de richting van scholen indien deze scholen voor bekostiging in aanmerking willen komen. Geconstateerd wordt dat de vrijheid van stichting in vergaande mate illusoir is geworden. Vervolgens gaat dit artikel in op alternatieven voor het huidige stelsel: richtingvrije planning en een verruiming van het richtingbegrip. Daarbij behandel ik ook de plannen van staatssecretaris Dekker van Onderwijs. Alvorens daarop in te gaan worden de begrippen stichting, richting en inrichting nader belicht.

\section{Stichting, richting en inrichting}

Zoals gezegd biedt het huidige stelsel van artikel 23 van de Grondwet aan burgers (ouders) en maatschappelijke organisaties de vrijheid om een school te stichten. Het idee hierachter is dat in de pluriforme (vroeger verzuilde) samenleving onderwijs naar eigen geaardheid en inzicht kan worden verzorgd. ${ }^{2}$ Onderwijs is immers niet alleen het bijbrengen van kennis, maar is ook Bildung, hetgeen niet los kan worden gezien van religie of levensbeschouwing. Het gevolg is dat het onderwijsaanbod de levensbeschouwelijke diversiteit in de samenleving weerspiegelt. ${ }^{3}$ Het

1 Uitgebreid: S.C. van Bijsterveld, 'Een vergeten episode uit de schoolstrijd: de ontdekking van “openbaar" en "bijzonder" onderwijs', TvRRB 2013, 4, p. 16-32.

2 Onderwijsraad, Artikel 23 Grondwet in maatschappelijk perspectief, Den Haag: Onderwijsraad 2012, p. 10.

3 R. Guldenmond, 'De toekomst van het begrip "richting" in de onderwijswetgeving', TvRRB 2015, 6, p. 36. 
stelsel, inclusief het bijzonder onderwijs, draagt daarom, aldus ook de Onderwijsraad, bij aan de ontwikkeling van de samenleving als geheel. ${ }^{4}$

Hieruit kunnen we afleiden dat de vrijheid van stichting, de vrijheid van richting en de vrijheid van inrichting nauw met elkaar samenhangen. Ouders en maatschappelijke organisaties maken gebruik van de vrijheid van stichting om aldus een richting tot uiting te brengen en de school op grond van die richting in te richten. Niettemin is het dogmatisch zinvol deze vrijheden te onderscheiden. De vrijheid van stichting houdt in dat ouders of maatschappelijke organisaties, met een bepaalde godsdienstige of levensbeschouwelijke overtuiging, een school kunnen stichten die voor overheidsbekostiging in aanmerking komt. De vrijheid van richting betreft de vrijheid een godsdienstige of levensbeschouwelijke overtuiging ten grondslag aan de school te mogen leggen. Het moet een erkende richting betreffen (zie de paragraaf Normen voor bekostiging). De vrijheid van inrichting is de vrijheid om de school te regelen, te beheren en te besturen naar eigen inzicht. De inrichting betreft onder meer: de pedagogische uitgangspunten, didactiek, toelatingsbeleid, aannamebeleid van leraren, enzovoort, enzovoort. Stichting, richting en inrichting houden, zoals gezegd, nauw verband met elkaar. Voor stichting van een school is de gekozen erkende richting van belang (zie de paragraaf Normen voor bekostiging). De richting van de school is bovendien bepalend voor haar inrichting: de richting ligt ten grondslag aan didactiek, toelatingsbeleid enzovoort.

\section{Normen voor bekostiging}

Om voor bekostiging in aanmerking te komen moet een school in de eerste plaats voldoen aan een stichtingsnorm en is in de tweede plaats de richting van de school van belang. ${ }^{5}$ De stichtingsnorm betreft het aantal leerlingen dat aan een school onderwijs moet krijgen. Scholen krijgen een bepaalde periode om dat aantal te behalen. Voor het primair onderwijs is dat vijf jaar, voor het voortgezet onderwijs de nominale cursusduur plus twee jaar (dus voor vwo zes + twee jaar). De stichtingsnormen liggen hoog: zo moet een vwo-school minimaal 390 leerlingen hebben, een havo $325^{6}$ en een basisschool, afhankelijk van de gemeente,

4 Onderwijsraad 2010, p. 10.

5 Er zijn ook andere voorwaarden van belang, maar die zijn minder relevant voor dit artikel. Zie uitgebreid: P. Bisschop \& M. Imandt, De (on)mogelijkheden voor nieuwe scholen in Nederland, Amsterdam: SEO 2015, zie seo.nl. Het navolgende in deze paragraaf is mede gebaseerd op mijn annotatie van ABRvS 21 augustus 2013, JB 2013, 189, en op: J.L.W. Broeksteeg, 'Artikel 23 en de school als onderwijsgemeenschap', in: B. Kamphuis, L. Kooistra \& M. Neuteboom, Het kind als 'project X', Christen Democratische Verkenningen 2015, p. 110-116. Art. 65 WVO. 
minimaal 200. ${ }^{7}$ De normen zijn de afgelopen decennia aanmerkelijk verhoogd vanwege een door de politiek gewenste schaalvergroting in het onderwijs. ${ }^{8}$

Naast deze normen geldt het richtingbegrip als bekostigingsfactor. Om voor bekostiging in aanmerking te komen moet er sprake zijn van een richting. De Grondwet noemt richting in het vijfde lid van artikel 23, maar geeft niet weer wat onder richting moet worden verstaan. Ook de wet (Wet op het primair onderwijs (WPO), Wet op het voortgezet onderwijs (WVO)) zwijgt over de inhoud van het richtingbegrip. Het begrip heeft vooral invulling gekregen in de jurisprudentie. Vanaf de jaren dertig van de vorige eeuw is richting consequent uitgelegd als godsdienst en levensovertuiging. ${ }^{9}$ Daar ligt geen expliciete beleidskeuze aan ten grondslag, maar deze uitleg is vooral een gevolg van de verzuiling. ${ }^{10}$ De 'erkenning' van een richting komt tot uiting in het besluit om een school van de desbetreffende richting te bekostigen. Deze besluiten, en de jurisprudentie die naar aanleiding daarvan is ontstaan, geven weer welke richtingen voor bekostiging in aanmerking komen.

Welke criteria past de rechter toe om te bepalen of sprake is van een richting? In 1933 oordeelde de Kroon dat bijzonder onderwijs 'uitgaat van richtingen, welke zich in het Nederlandse Volk op geestelijk terrein openbaren'. ${ }^{11}$ In 1983 oordeelde de Kroon dat richting betrekking heeft op 'de inhoud van het onderwijs, zoals die wordt beïnvloed door een op alle terreinen des levens doorwerkende godsdienstige overtuiging of levensbeschouwing' ${ }^{12}$ De Afdeling voor de geschillen van bestuur van de Raad van State (AGRvS) oordeelde in 1992 dat sprake moet zijn van 'een brede, geestelijke - van de bestaande richtingen in het voortgezet onderwijs te onderscheiden - stroming in de Nederlandse samenleving'. ${ }^{13}$ De Afdeling bestuursrechtspraak van de Raad van State (ABRvS) omschreef richting in 1997 als 'een aan het onderwijs ten grondslag liggende geestelijke stroming die zich in een binnen Nederland waarneembare beweging openbaart en ook op andere terreinen van het leven doorwerkt'. ${ }^{14}$ In 2010 definieerde de Hoge Raad richting als 'een fundamentele oriëntatie, ontleend aan een welbepaalde godsdienstige overtuiging of levensbeschouwing. ${ }^{15}$ Er moet, kortom, sprake zijn van een brede beweging of stroming op geestelijk terrein, die waarneembaar is en doorwerkt op allerlei terreinen van het leven. Richting kan, met andere woorden,

$7 \quad$ Zie art. 77 WPO.

8 Zo ook eerder al: H. Drop, Handboek van het Nederlandse onderwijsrecht, bew. door A. Postma, Zwolle: W.E.J. Tjeenk Willink 1995, p. 113; P.J.J. Zoontjens, Inleiding tot de onderwijswetgeving, Den Haag: Elsevier 1999, p. 53.

9 Hierna, bij de richtingvrije planning, gaan wij in op de periode vóór 1930.

10 P.W.A. Huisman, M.T.A.B. Laemers, D. Mentink \& P.J.J. Zoontjens, Vrijheid van stichting, rapport 2011, p. 58-59, te raadplegen op https://research.vu.nl/en/publications/vrijheid-vanstichting.

11 KB 15 mei 1933, $A B$ 1933, 543.

12 KB 11 november 1983, $A B$ 1984, 109.

13 AGRvS 10 november 1992, AB 1993, 88, m.nt. Van der Net.

14 ABRvS 11 februari 1997, AB 1998, 28, m.nt. Vermeulen.

15 HR 6 juli 2010, NJ 2010/422. 
geen maatschappelijke stroming betreffen, maar vereist wel maatschappelijk draagvlak.

Bijvoorbeeld: de jurisprudentie aanvaardde onderwijs op evangelische grondslag pas in 1997 als richting, toen de evangelische stroming ook buiten het onderwijs was verankerd in de samenleving, zoals in de politiek (RPF) en de omroepen (EO). ${ }^{16}$ Pas in de jaren negentig werden islamitisch en hindoeïstisch onderwijs als een richting beschouwd; boeddhistisch, koptisch of remonstrants onderwijs is dat (nog steeds) niet. Kennelijk zijn deze toch geïnstitutionaliseerde godsdiensten nog onvoldoende te beschouwen als brede, maatschappelijke stromingen die ook op andere terreinen van het leven (omroepen, politieke partijen, maatschappelijke organisaties) doorwerken. Erkend zijn onderwijs op rooms-katholieke, algemeen christelijke, evangelische, evangelisch broedergemeentelijke, reformatorische, protestants-christelijke, gereformeerde (vrijgemaakt), joodse, hindoeïstische, islamitische, antroposofische en algemeen-bijzondere ${ }^{17}$ grondslag. De Onderwijsraad heeft in 2014 geadviseerd om het humanisme als grondslag te erkennen. ${ }^{18}$ Een jaar later startte een humanistische mavo in Amsterdam.

Naast de stichtingsnorm en het richtingbegrip geldt dat de te stichten school een van de bijzondere scholen in de omgeving ${ }^{19}$ te onderscheiden richting moet hebben of dat er op de reeds bestaande school van dezelfde richting onvoldoende plek is. Het is daarom onmogelijk om een nieuwe rooms-katholieke school voor voortgezet onderwijs te stichten in Den Bosch of een nieuwe school voor protestantschristelijk onderwijs in Veenendaal. Alleen voor nieuwe richtingen of in nieuwbouwwijken geldt dat het nog kansrijk is een nieuwe school te stichten. Dat kan problematisch zijn, omdat ouders bijvoorbeeld een reformatorische school willen oprichten die minder orthodox is dan de bestaande school in de desbetreffende regio, of juist meer aandacht willen besteden aan catechese omdat zij menen dat de bestaande rooms-katholieke scholen dat onvoldoende doen. ${ }^{20}$ Dat geeft weer dat de huidige interpretatie van het richtingbegrip 'op slot' zit.

Omdat het richtingbegrip op slot zit, worden listige constructies verzonnen: een school neemt dan meerdere richtingen aan, om aldus aan het minimumaantal leerlingen te komen. In Hengelo is weliswaar openbaar en rooms-katholiek voortgezet onderwijs, maar nog geen school op een gecombineerde gereformeerde, algemeen-bijzondere en vrije grondslag. De te stichten en te bekostigen school neemt daarom al deze drie richtingen aan. In Hurdegaryp en Harderwijk zijn geen scholen voor voortgezet onderwijs met een rooms-katholieke en algemeen-bijzondere signatuur. Het schoolbestuur kan deze verschillende richtingen combineren, ook al hebben die richtingen nauwelijks samenhang. De scholen zijn, kortom, op

16 ABRvS 11 februari 1997, AB 1998, 28, m.nt. Vermeulen.

17 Algemeen-bijzonder onderwijs is bijzonder, dus door particulieren geïnitieerd, beheerd en bestuurd onderwijs, dat niet is gegrond op een godsdienst of levensbeschouwing.

18 Onderwijsraad, Humanisme als richting, 26 maart 2014, www.onderwijsraad.nl/publicaties/2014/ humanisme-als-richting.

19 De regio bedraagt voor het primair onderwijs 10 kilometer: art. 75 WPO.

20 Vergelijk: Guldenmond 2015, p. 51. 
zoek naar witte vlekken op de kaart. Daarbij is de richting een kapstok: het gaat deze scholen niet om rooms-katholiek of protestants-christelijk onderwijs, maar om nieuwe pedagogische concepten. Die kunnen echter niet als bekostigingsvoorwaarde gelden, vandaar deze noodgreep. De rechter laat het 'stapelen' van richtingen toe, zelfs als die geen of nauwelijks samenhang hebben, soms zelfs tegenstrijdig aan elkaar zijn. ${ }^{21}$

De conclusie moet zijn dat het nauwelijks nog mogelijk is om een school op te richten die voor bekostiging in aanmerking komt. De stichtingsnormen zijn te hoog en het richtingbegrip zit op slot. Dat staat op gespannen voet met artikel 23 Grondwet. Dat artikel maakt het immers mogelijk dat burgers scholen kunnen oprichten. De stichtingsnormen en de huidige interpretatie van het richtingbegrip maken de uitoefening van het grondrecht illusoir.

\section{Een ruimer richtingbegrip}

Het is de vraag op welke wijze nieuwe invulling gegeven kan worden aan de vrijheid van stichting. Zoals in de inleiding is aangegeven, is die vrijheid belangrijk, om aldus de maatschappelijke pluriformiteit ook in het onderwijs tot uiting te laten komen. Dat is, zoals de Onderwijsraad constateerde, een belang dat de samenleving aangaat.

De sleutel zou een verruiming van het richtingbegrip kunnen zijn, overigens altijd in combinatie met andere maatregelen, zoals een verlaging van het getalscriterium bij de oprichting van scholen. Richting kan nu alleen betrekking hebben op godsdienst en levensovertuiging: niet alleen is artikel 23 Grondwet zo ingericht dat bijzonder en openbaar onderwijs elkaars spiegelbeeld zijn, maar ook is in de relevante jurisprudentie (hiervoor weergegeven) het begrip richting duidelijk verbonden met godsdienst en levensovertuiging.

Er zijn grosso modo twee modaliteiten. Het richtingbegrip kan zodanig worden verruimd dat daaronder niet alleen godsdienstige en levensbeschouwelijke stromingen vallen, maar bijvoorbeeld ook pedagogisch-didactische (zie de subparagraaf Een verruimd richtingbegrip). De andere mogelijkheid is dat het richtingbegrip niet meer relevant is voor het oprichten van een school, de zogeheten richtingvrije planning. Richting is dan, anders gezegd, geen bekostigingsfactor meer (zie de subparagraaf Richtingvrij plannen). Beide mogelijkheden betekenen een fundamentele herinterpretatie van artikel 23 Grondwet. Aanpassing van dit artikel is strikt genomen niet nodig, omdat de huidige interpretatie van het richtingbegrip immers in de jurisprudentie tot stand is gekomen. Illustratief is dat onder de Lager Onderwijswet tot 1920 ook een stelsel van richtingvrije planning gold: de richting van de school was niet relevant voor bekostiging. Daarvóór gold alleen of er voldoende belangstelling van ouders was. ${ }^{22}$ De jurisprudentie die de huidige 
interpretatie van het richtingbegrip weergeeft, is in de jaren dertig tot stand gekomen.

\section{Richtingurij plannen}

De discussie over richtingvrij plannen is niet nieuw. De situatie onder de Lager Onderwijswet tot 1920 wordt vaak als voorbeeld gegeven van een stelsel van richtingvrij plannen. Voor de discussie zoals die heden ten dage gevoerd wordt, valt te verwijzen naar het rapport Richtingurij en richtingbepalend van de Onderwijsraad, uit 1996. ${ }^{23}$ Hierin bepleit de raad de afschaffing van het richtingbegrip als ordeningsprincipe, omdat de overheid terughoudend zou moeten zijn ten aanzien van godsdienst en levensovertuiging, met richtingvrije planning de vrijheid van onderwijs maximaal als grondrecht kan worden ingevuld en het steeds moeilijker wordt om tot een aanvaardbaar oordeel te komen of sprake is van een nieuwe richting. In een reactie op het rapport stelde het kabinet het voorstel te willen overnemen - hetgeen overigens niet gebeurd is. ${ }^{24}$ Ook meer recent, in 2012, adviseerde de Onderwijsraad in zijn rapport Artikel 23 Grondwet in maatschappelijk perspectief tot invoering van richtingvrije planning. Hij stelt vast dat artikel 23 Grondwet nog steeds van grote maatschappelijke waarde is. Het duale onderwijsstelsel biedt keuzevrijheid voor ouders en het biedt sociale samenhang in de huidige pluriforme samenleving. Wel meent de Onderwijsraad dat de huidige interpretatie van het begrip 'richting' onvoldoende inspeelt op die steeds grotere pluriformiteit. ${ }^{25}$ Het is, zeker voor godsdiensten die relatief nog maar kort in de samenleving voorkomen, moeilijk om een school bekostigd te krijgen, omdat zij niet snel als richting erkend worden. De desbetreffende godsdienst moet immers op allerlei terreinen van de samenleving 'doorwerken'. De Onderwijsraad overweegt dat het mogelijk zou moeten zijn om scholen te stichten op grond van een pedagogische opvatting of op grond van relatief nieuwe godsdienstige of levensbeschouwelijke overtuigingen. ${ }^{26} \mathrm{Om}$ een school te stichten zou enkel het aantal leerlingen maatgevend moeten zijn: de school moet voldoende leerlingen trekken. De Onderwijsraad kiest er dus voor om de richting geen rol meer te laten spelen bij de oprichting van scholen.

Ook nu heeft het kabinet de plannen van de Onderwijsraad omarmd. Staatssecretaris Dekker heeft in 2012 een brief aan de Tweede Kamer gezonden waarin hij verdedigt dat een school niet meer vanuit een bepaalde religieuze of levensbeschouwelijke visie opgericht hoeft te worden. ${ }^{27}$ Hij betoont zich voorstander van richtingvrije planning: 'Hierdoor zal het scholenbestand in de toekomst een betere weerspiegeling van de samenleving zijn.' De plannen van de staatssecretaris zijn echter breder dan alleen het vrijgeven van het richtingbegrip. Zo wil hij het mogelijk maken dat een school 'van kleur kan verschieten', met andere woorden dat de school op verzoek van een (grote) meerderheid van de ouders een 
andere richting aanneemt. Er zou voorts initiatiefrecht bij de ouders moeten liggen om een nieuwe openbare school te stichten, bijzondere scholen zouden aan een acceptatieplicht van leerlingen moeten voldoen en thuisonderwijs mag onder geen beding meer. Deze punten vallen strikt genomen buiten het bestel van deze bijdrage. Zij roepen nochtans de nodige vragen en problemen op. Zoals het 'van kleur verschieten': wat te doen met het personeelsbestand van leraren die bewust voor (bijvoorbeeld) een protestants-christelijke school hebben gekozen die nu humanistisch wordt, wat te doen met de minderheid van (ouders van) leerlingen die bewust voor de signatuur heeft gekozen die nu wordt gewijzigd, met de onderwijsmethoden die op de richting berusten, enzovoort. Het lijkt erop dat de staatssecretaris zich er onvoldoende van bewust is dat de richting van de school in vergaande mate de inrichting bepaalt. En wat te denken van het initiatiefrecht voor een openbare school: ouders hadden al het recht om een school op algemeen-bijzondere grondslag te stichten. Het is dan de vraag wat dit voorstel toevoegt en bovendien wat de zinsnede 'van overheidswege' in artikel 23 lid 4 Grondwet nog betekent.

Wat daarvan ook zij, de staatssecretaris heeft het voorstel van wet 'Meer ruimte voor nieuwe scholen' ter internetconsultatie voorgelegd. In de toelichting bepleit de staatssecretaris een herinterpretatie van het richtingsbegrip van artikel 23 Grondwet, waardoor richtingvrije planning ontstaat en een grotere variëteit van scholen. Het begrip richting wordt op verschillende plaatsen in de onderwijswetten geschrapt. Het speelt geen rol meer voor bekostiging. Het wetsvoorstel voorziet in een leerlingenprognose op basis van ouderverklaringen of marktonderzoek. Daarnaast wil het voorstel voorzien in waarborgen voor kwaliteit voor nieuwe scholen, hetgeen nu onvoldoende getoetst zou kunnen worden. ${ }^{28}$

Richtingvrije planning is tot op heden, ondanks alle rapporten, adviezen en voorstellen, niet gerealiseerd. De verklaring is - vermoedelijk - de volgende. In een stelsel van richtingvrije planning is een erkende richting niet langer essentieel voor de oprichting van een bekostigde school. Alleen het aantal ouderverklaringen, waarin ouders weergeven dat hun kind onderwijs gaat volgen aan de op te richten school, is leidend. Immers, als richting niet meer geldt, gelden nog slechts de stichtingsnormen, oftewel het aantal kinderen dat de school bezoekt. Het is echter moeilijk te definiëren welke ouders de verklaring kunnen geven, waaruit die ouderverklaringen kunnen blijken, enzovoort. Het kabinet stelde voor dat de ouderverklaringen ondertekend zouden moeten worden ten overstaan van een ambtenaar van de gemeente, die de gegevens controleert, en dat de verklaringen één jaar geldig zouden zijn. Voor het primair onderwijs zouden de ouderverklaringen de leerlingen moeten betreffen die jonger zijn dan 8 jaar en van wie ten minste de helft tussen $2^{1 / 2}$ en 4 jaar oud moet zijn. Voor het voortgezet onderwijs moesten de ouderverklaringen kinderen betreffen tussen 9 en 14 jaar oud, van wie de helft tussen 10 en 12 jaar is. ${ }^{29}$ Deze voorwaarden lijken gedetailleerd, maar roepen nochtans vragen op. Wat zou, bijvoorbeeld, de maximale afstand tussen

28 Zie www.internetconsultatie.nl/meerruimtevoornieuwescholen.

29 Kamerstukken II 1996/97, 25167, 1, p. 10-12. 
het woonadres en de school mogen zijn? Mag een ouder meerdere verklaringen voor meerdere schoolinitiatieven tekenen? Als algemeen bezwaar van ouderverklaringen geldt dat aan de voorspellende waarde daarvan ernstig wordt getwijfeld. De verklaringen geven geen zekerheid dat de desbetreffende kinderen de op te richten school daadwerkelijk gaan bezoeken. De ouders van de kinderen kunnen daartoe ook niet worden verplicht, al was het maar vanwege de schoolkeuzevrijheid zoals vastgelegd in artikel 2 Eerste Protocol van het Europees Verdrag voor de Rechten van de Mens (EVRM). ${ }^{30}$

Er zijn nog meer problemen. Zo is het de vraag in hoeverre het risico van leegloop van bestaande scholen te beteugelen valt indien de oprichting van een school veel gemakkelijker te realiseren valt. Principiëler is het bezwaar dat een school zonder richting niet bij voorbaat gericht hoeft te zijn op continuïteit. De ouders van de hockeyclub kunnen, gechargeerd gezegd, in dat stelsel gezamenlijk een 'ons soort mensen'-school oprichten. Zo'n school hoeft echter geen (duidelijke) koers te hebben en is, door het ontbreken van een richting, meer 'los zand': er hoeft geen richting meer te zijn als funderend en organiserend beginsel voor de oprichting en de inrichting van de school. ${ }^{31}$ Wat dat bijvoorbeeld voor het toelatingsbeleid van leerlingen betekent, is maar de vraag.

\section{Een verruimd richtingbegrip}

Een alternatief voor richtingvrije planning is een verruiming van het richtingbegrip. Dat houdt in dat richting nog steeds bepalend is voor de oprichting van een bekostigde school, maar dat richting niet langer beperkt is tot godsdienst of levensbeschouwing. Daartoe zou er ook een pedagogische of didactische invulling aan gegeven kunnen worden. Richting zou dan kunnen zijn: een samenhangend pedagogisch concept, gestoeld op een mensbeeld dat vormgevend is aan onderwijs en opvoeding. ${ }^{32}$ Scholen worden geacht dat concept in hun statuten vast te leggen. Richting blijft aldus een bekostigingsfactor. Richtingvrij is derhalve een wezenlijk ander concept dan een verruiming van het richtingbegrip. Het voordeel van een verruiming van het richtingbegrip is dat, in tegenstelling tot de richtingvrije planning, het nog steeds een conceptueel mens- en maatschappijbeeld veronderstelt dat vormgevend is aan onderwijs en opvoeding. Het betreft dan een onderwijsconcept dat door een groep ouders (en anderen) gezamenlijk wordt voorgestaan. Het gaat er, met andere woorden, om ouders samen te brengen rond een gezamenlijk beleefd mens- en maatschappijbeeld.

Aan verruiming van het richtingbegrip kleven eveneens nadelen. Zo zou het openbaar onderwijs een richting krijgen als het van een specifiek pedagogisch-didactisch concept uitgaat. Ook zou een school meerdere richtingen kunnen hebben,

30 B.P. Vermeulen, 'Vraagstukken rondom de vrijheid van onderwijs', in: T.J. van der Ploeg e.a. (red.), De vrijheid van onderwijs, de ontwikkeling van een bijzonder grondrecht, Utrecht: Lemma 2000, p. 285.

31 Van Bijsterveld 2014, p. 4.

32 Advies Commissie Onderwijsstelsel, Bevrijd de onderwijsdieren, Woerden: Bond KBO en Bond KBVO 2011. 
omdat zowel de godsdienstige als de pedagogische richting kan. Denk aan een school op rooms-katholieke grondslag met montessorionderwijs. Dat roept moeilijkheden op: kunnen bijvoorbeeld bij stichting beide richtingen meetellen voor de stichtingsnorm? Akkermans meent dat deze bezwaren te veel het perspectief van de overheid weergeven. ${ }^{33}$ Daarin heeft hij gelijk als het om het doel van verruiming gaat: het openbreken van het richtingbegrip waardoor ouders (en maatschappelijke organisaties) vrijer worden om scholen op te richten. Anderzijds is het moeilijk te verdedigen dat zich in een regio vele (bekostigde) rooms-katholieke scholen vestigen, die zich enkel onderscheiden met (of elkaar beconcurreren op grond van) hun pedagogische visie. Een ander bezwaar zou de rol van de overheid kunnen zijn. Het is vanzelfsprekend primair aan de dragers van de vrijheid van onderwijs om te bepalen of hun samenhangend pedagogisch concept, hun stroming derhalve, als een richting kan worden aangemerkt. Maar de overheid $\mathrm{zal}$, al was het maar vanwege de bekostiging, moeten toetsen of hier sprake is van een serieuze richting. Zij zal dat, uit de aard der zaak, slechts marginaal kunnen doen en aan de hand van zo veel mogelijk niet-inhoudelijke criteria. De rol van de overheid bij erkenning van het richtingbegrip is kleiner dan thans het geval is, maar groter dan bij richtingvrij plannen.

\section{Slot}

De vrijheid om scholen op te richten, een onmisbaar element van de vrijheid van onderwijs, is illusoir geworden. De stichtingsnormen zijn hoog en de huidige interpretatie van het richtingbegrip lijkt onvoldoende aan te sluiten bij de hedendaagse pluriforme samenleving. Tegelijkertijd zien we dat aan het meest voor de hand liggende alternatief, namelijk richtingvrij plannen, wezenlijke nadelen kleven. Dat zijn praktische bezwaren - ouderverklaringen zijn onvoldoende betrouwbaar - en principiële bezwaren - een school zonder richting kent geen funderend en organiserend beginsel. Ook een verruiming van het richtingbegrip is niet zonder nadelen: de overheid zal, hoe marginaal ook, moeten toetsen of sprake is van een voldoende samenhangend concept om als richting te kunnen gelden, en een school zou meerdere richtingen kunnen hebben. Groot voordeel van een verruiming van het richtingbegrip is dat het, in tegenstelling tot de richtingvrije planning, nog steeds een conceptueel mens- en maatschappijbeeld als grondslag voor het onderwijs en de overige inrichting van de school veronderstelt. Het gevaar van de school als 'los zand' is minder aanwezig dan bij richtingvrije planning. Bovendien lijkt mij dat aan elk onderwijs een funderend mens- en maatschappijbeeld ten grondslag ligt (of behoort liggen). In dat opzicht lijkt een verruiming van het richtingbegrip meer voor de hand te liggen dan het volledig loslaten daarvan.

33 P.W.C. Akkermans, 'Schaalvergroting, decentralisatie en richting: een verenigbare verzameling?', in: T.J. van der Ploeg e.a. (red.), De vrijheid van onderwijs, de ontwikkeling van een bijzonder grondrecht, Utrecht: Lemma 2000, p. 162. 